\title{
FONTES DE INFORMAÇÃO ESPECIALIZADAS EM MARCAS: UM OLHAR BIBLIOTECONÔMICO
}

\author{
SOURCES OF INFORMATION SPECIALIZED IN \\ BRANDS: A LIBRARY SCIENCE OUTLOOK
}

\author{
Mylena Cristhina Araujo de Oliveira a \\ Nysia Oliveira de Sáb \\ Evanildo Vieira dos Santos ${ }^{\circ}$
}

\begin{abstract}
RESUMO
Introdução: A disponibilização e a organização da informação na base de dados de marcas do Instituto Nacional da Propriedade Industrial (INPI) são singulares, se comparadas às fontes de informação tradicionalmente conhecidas, no esquema de metadados Dublin Core (DC). Objetivo: Analisar se a estrutura de armazenamento de dados das fontes de informação específicas de marcas do INPI possibilita, de forma eficiente e eficaz, o acesso e a recuperação da informação, tais como recomendados pelo esquema de metadados DC. Metodologia: Adota-se abordagem qualitativa, tendo como técnica análise comparativa dos elementos do padrão Dublin Core com os campos e subcampos do Sistema de Marcas do INPI. Resultados: As descrições de dados especializados em marcas não se adequam aos padrões recomendados para a descrição de objetos digitais. Conclusão: É exequível a adequação do Sistema de Marcas ao esquema de metadados Dublin Core, desde que, previamente, sejam realizados estudos para identificar as necessidades informacionais dos usuários e treinar bibliotecários em Propriedade Industrial, possibilitando criar condições para facilitar o acesso, a busca e a recuperação da informação.
\end{abstract}

Descritores: Marcas. Propriedade industrial. Fonte de informação. Dublin Core. Metadados.

a Bacharel em Biblioteconomia e Gestão de Unidades de Informação.

Universidade Federal do Rio de Janeiro (UFRJ). E-mail: mycristh@gmail.com.

b Doutor em Políticas públicas e formação humana pela Universidade do Estado do Rio de Janeiro (UERJ). Docente no curso de Biblioteconomia e Gestão de Unidades de Informação da Universidade Federal do Rio de Janeiro (UFRJ). E-mail: nysia@facc.ufrj.br.

c Doutor em Propriedade Intelectual e Inovação, pela Academia da Propriedade Intelectual e Inovação do Instituto Nacional da Propriedade Industrial (INPI). Bibliotecário-Gestor e responsável técnico da Biblioteca de Propriedade Intelectual e Inovação do Instituto Nacional da Propriedade Industrial (INPI). E-mail: evanildo@inpi.gov.br. 


\section{INTRODUÇÃO}

As marcas são cada vez mais reconhecidas como valiosos patrimônios de uma organização, sendo capazes de distinguir corporações, produtos e serviços (VÁSQUEZ, 2007). A contínua expansão mercadológica propiciou, entre outros fatores, crescente surgimento de novas empresas e marcas disponíveis no mercado e, ligada à essa expansão, surge a necessidade de proteção dessas marcas.

Atualmente, tais marcas são entendidas como pertencentes ao universo da Propriedade Intelectual $(\mathrm{PI})$ - produção resultante da capacidade inventiva ou criadora do intelecto humano -, também podendo ser desdobrada em Propriedade Industrial - produção ligada ao âmbito empresarial (INPI, 2019). Nesse aspecto, segundo a Lei da Propriedade Industrial do Brasil (Lei n. 9.279/96), as marcas são objetos passíveis de proteção, assegurando, assim, direitos exclusivos para os detentores de seus registros.

No Brasil, o Instituto Nacional da Propriedade Industrial (INPI) é responsável pelo registro e concessão de marcas em todo o território nacional. No contexto internacional tem-se a Organização Mundial da Propriedade Intelectual (OMPI).

Identifica-se crescimento significativo de registro de marcas no Brasil que resulta, segundo relatório de atividades do INPI (2019), de um conjunto de fatores como: capacitação de servidores para o exame de pedidos; redução entre os tempos de depósito e o primeiro exame; negociações internacionais; consciência dos depositantes sobre a importância do registro de uma marca etc.

Nesta perspectiva, as instituições responsáveis por essas atividades necessitam de bases de dados capazes de armazenar os dados referentes às marcas, uma vez que as mesmas, nesse contexto, são tratadas como documentos.

Além disso, para o registro das marcas em bases de dados, é necessário que haja uma padronização, organizada por meio de uma estrutura de campos e subcampos, capazes de armazenar os dados no sistema, a fim de tornar possível uma eficiente recuperação da informação. No entanto, observa-se que 
as estruturas de documentação das marcas são diferentes das estruturas de outros documentos bibliográficos.

Assim, o objetivo desse estudo é analisar se a estrutura de armazenamento de dados das fontes de informação específicas de marcas do INPI possibilita, de forma eficiente e eficaz, acesso e recuperação de informação. Para tanto, como elemento comparativo optou-se pelo padrão de metadados Dublin Core (DC) e os seus 15 elementos, que é o padrão mais utilizado no momento nas fontes de informação de bibliografias eletrônicas.

\section{DEFINIÇÃO DE MARCA}

De acordo com Vallegros (2011) a palavra marca é a tradução do termo anglo-saxônico brand, que tem sua origem no antigo escandinavo brandr. O seu significado era ligado ao ato de queimar, que correspondia à marcação de gado realizada por fazendeiros a fim de identificar a propriedade e a posse de bens.

Para o INPI (2019, não paginado), "[...] marca é um sinal distintivo cujas funções principais são identificar a origem e distinguir produtos ou serviços de outros idênticos, semelhantes ou afins de origem diversa.". Assim, a marca é um sinal singular, visualmente perceptível pelo uso de nome; termo; símbolo; grupo de palavras e letras; desenho ou combinação dos elementos descritos, usado para fazer a distinção entre os produtos e/ou serviços similares ou idênticos oferecidos no mercado.

Ressalte-se que, com seu uso no mercado, as marcas se diferenciam por sua natureza: marcas de produtos; de serviços; coletiva e de certificação. As marcas de produtos e serviços são utilizadas para identificar produtos ou serviços provenientes de uma fonte comercial, e diferenciá-los dos demais idênticos ou assemelhados, que provenham de outras fontes. As coletivas identificam os produtos e/ou serviços disponibilizados por uma entidade coletiva, que deverá requerer o registro da marca e estabelecer condições de uso para seus membros associados por meio de um regulamento de utilização. Já as marcas de certificação, atestam a conformidade com a qualidade, o modo de fabricação, a origem etc. de produtos ou serviços de acordo com determinadas 
normas, padrões ou especificações técnicas (INPI, 2019).

As marcas também podem ser designadas como: marcas notoriamente conhecidas, que são aquelas de expressivo conhecimento público, em que um comprador ou usuário potencial é capaz de reconhecer ou se lembrar daquela marca como integrante de uma certa categoria de produtos ou serviços disponíveis no mercado; ou de alto renome, aquelas conhecidas por consumidores de diferentes segmentos do mercado que não apenas ao de atuação das marcas em questão (INPI, 2019).

No que se refere às formas gráficas de apresentação, o INPI (2019) declara que as marcas podem ser classificadas em nominativa, figurativa, mista e tridimensional. A marca nominativa é um sinal formado por uma ou mais palavras pertencentes ao alfabeto romano; compreende, também, neologismos e combinações de letras e/ou algarismos romanos e/ou arábicos, desde que não se apresentem de forma fantasiosa ou estilizada. A figurativa é constituída por desenhos; figuras; símbolos; imagens; ideogramas; palavras pertencentes a alfabetos distintos; e forma fantasiosa de letras ou algarismos. A marca mista é a composta pela combinação de elementos nominativos e figurativos ou de elementos nominativos que se apresentem de forma fantasiosa e estilizada. Já a tridimensional é aquela constituída pela forma plástica, que é a configuração ou a conformação física de produto ou de embalagem, cuja forma tenha capacidade distintiva.

\section{UMA BREVE HISTÓRIA DA MARCA}

A humanidade, desde os primórdios, se utiliza de símbolos para se expressar e passar uma determinada mensagem. Mesmo nos primeiros modelos de civilização, artesãos já assinavam suas obras a fim de evitar cópias e para diferenciar seus produtos dos demais que eram comercializados. Com o passar do tempo e o desenvolvimento do comércio, deu-se o aumento da utilização das marcas (INPI, 2016).

Remonta ao século XIX, principalmente na Inglaterra, Estados Unidos e Alemanha, as preocupações quanto a proteção e ao registro das marcas. 
Segundo Pinho (1996), a legislação de proteção às marcas era lenta e confusa, uma vez que as marcas não eram bens tangíveis. Porém, em 1862 foi promulgada a Lei de Marcas de Mercadoria na Inglaterra; em 1870 foi a vez da Lei Federal de Marcas de Comércio nos Estados Unidos; e em 1874 a Lei para a Proteção de Marcas na Alemanha. Vale ressaltar que, no Brasil, o Código Criminal do Império era omisso no que diz respeito à proteção legal das marcas.

Com o passar dos séculos, e o exponencial crescimento do mercado e a grande quantidade e variedade de produtos e serviços disponíveis, o registro das marcas se tornou indispensável para a proteção das mesmas. Atualmente, as marcas são um dos objetos passíveis de proteção por parte da Propriedade Industrial no Brasil (INPI, 2019). A partir de 1967, constitui-se nas Nações Unidas um órgão autônomo intitulado Organização Mundial da Propriedade Intelectual (OMPI) ou, na versão inglesa, World Intellectual Property Organization (WIPO). No Brasil, o órgão especializado em Propriedade Industrial foi criado em 1970, tratando-se do Instituto Nacional da Propriedade Industrial.

\section{A ORGANIZAÇÃO MUNDIAL DA PROPRIEDADE INTELECTUAL E O INSTITUTO NACIONAL DA PROPRIEDADE INDUSTRIAL}

A OMPI é uma das 16 agências especializadas da Organização das Nações Unidas (ONU), criada em 1967, com sede em Genebra. É um fórum global para serviços de propriedade intelectual, política, informação e cooperação. É também uma agência de autofinanciamento das Nações Unidas, com 191 Estados Membros, incluindo o Brasil. A agência se dedica à constante atualização e proposição de padrões internacionais de proteção às criações intelectuais em âmbito mundial. A sua missão é liderar o desenvolvimento de um sistema internacional de PI equilibrado e eficaz que permita a inovação e a criatividade para o benefício de todos (NAÇÕES UNIDAS BRASIL, 2019).

Por sua vez, o INPI foi criado em 1970 e é uma autarquia federal vinculada ao Ministério da Economia com sede na cidade do Rio de Janeiro. Possui como missão estimular a inovação e a competitividade a serviço do desenvolvimento tecnológico e econômico do Brasil, por meio da proteção eficiente da propriedade 
industrial. O Instituto oferece alguns serviços como os registros de marcas, desenhos industriais, indicações geográficas, programas de computador e topografias de circuitos integrados, as concessões de patentes e as averbações de contratos de franquia e das distintas modalidades de transferência de tecnologia (INPI, 2019).

\section{A PROPRIEDADE INTELECTUAL E A PROPRIEDADE INDUSTRIAL}

O termo Propriedade Intelectual não é formalmente definido pela OMPI, porém ele pode ser entendido como toda a produção que resulte da capacidade inventiva ou criadora do intelecto humano. Barbosa (2003) afirma que a soma dos direitos relativos à PI está relacionada à "[...] atividade intelectual nos domínios industrial, científico, literário e artístico. (BARBOSA, 2003, p. 10).

Entende-se, portanto, que a PI compreende os seguintes campos: Propriedade Industrial, Direito Autoral e Sui Generis. Para esse estudo, é relevante apenas o campo da Propriedade Industrial, que engloba: marcas; patentes; desenho industrial; indicação geográfica; e repressão à concorrência desleal (INPI, 2016, p. 5-6).

Os direitos obtidos por meio da PI são de fundamental relevância, já que tornam possível proporcionar retorno econômico para quem investe esforço e trabalho no desenvolvimento de criações intelectuais. "Ao proteger os direitos de Propriedade Intelectual estimulam-se as atividades desse gênero e 0 desenvolvimento de empresas dedicadas à exploração dessas criações." (INPI, 2016, p. 11).

\section{FONTES DE INFORMAÇÃO}

A palavra "comunicação" vem do latim "communicare", que significa partilhar ou tornar comum (LIESEN, 2014). O ato de comunicar implica na troca de mensagens, que por sua vez envolve emissão e recebimento de informações entre um comunicador e um intérprete a partir da utilização de signos e símbolos.

Desde os primórdios da humanidade a comunicação desempenhou um 
papel de muita importância e poder. Torquato (1991, p.162) cita que "[...] a comunicação é uma ferramenta importante de eficácia e produtividade.". Tal afirmativa se mostra verídica uma vez que é possível, com o uso da comunicação, convencer, persuadir, influenciar, despertar interesses e sentimentos, além de provocar expectativas.

A partir disso, é possível estabelecer uma ligação entre as marcas e o conceito de comunicação aqui tratado. As marcas se apresentam como ferramentas comunicacionais de uma organização por serem capazes de passar uma determinada mensagem ao público alvo de forma a atrair, inferir emoções diversas, etc. Com isso, pode-se dizer que o emissor é a empresa que utiliza a marca para passar uma mensagem a fim de atrair clientela; o receptor é o público alvo ou a própria clientela; e o código são os sinais que constituem a marca.

Tem-se a informação como um fenômeno da comunicação. Entretanto, informação é um termo de difícil conceituação devido à amplitude semântica e as diversas perspectivas de análise, domínios e concepções de cada área. Para fins dessa pesquisa, considera-se informação como dados apresentados sob forma legível aos quais foram atribuídos significados dentro de um contexto para seu uso (REITZ, 2001).

No que diz respeito às fontes de informação, Morigi e Bonotto (2004) afirmam que são:

[...] todos os materiais ou produtos, originais ou elaborados, que trazem notícias ou testemunhos, através dos quais se acessa o conhecimento, qualquer que seja este. [...] tudo aquilo que forneça uma notícia, uma informação ou um dado. [...] se encontram todos aqueles elementos que, submetidos à interpretação, podem transmitir conhecimento, tais como um hieróglifo, uma cerâmica, um quadro, uma partitura musical, uma fotografia, um discurso, uma tese doutoral e outros. (SAINERO, 1994 apud MORIGI; BONOTTO, 2004, p. 144).

$O$ acesso a essas fontes pode se dar diretamente (de forma oral), através de documentos ou mesmo através da internet (CAMPELLO; CENDÓN; KREMER, 2000). Na literatura da área de Biblioteconomia e Ciência da Informação, categorizam-se as fontes de informação em: primárias, secundárias e terciárias.

Tem-se, então, que as marcas são fontes primárias de informação, uma 
vez que as reconhecemos como um produto informacional elaborado por uma organização que se reconhece como detentora da marca, ou seja, é uma informação que vem diretamente da fonte e não é adulterada. Já as bases de dados de marcas são fontes secundárias, pois "[...] contêm informações sobre documentos primários e são arranjados segundo um plano definitivo; são, na verdade, os organizadores dos documentos primários e guiam o leitor para eles." (CUNHA, 2001, p. ix).

Vale destacar que, segundo Cunha (2001, p. 35), "Bases de dados é a expressão utilizada para indicar a coleção de dados que serve de suporte a um sistema de recuperação de informação.". Tem-se, então, como objetivos das bases de dados o fornecimento de informação atualizada, precisa, confiável e de acordo com a demanda (ALBRECHT; OHIRA, 2000, p. 133). Também é fundamental que essas bases, além de armazenar os dados, forneçam eficientes mecanismos de recuperação da informação.

\section{METADADOS E O PADRÃO DUBLIN CORE}

Metadado é definido por Gilliland (2016) como dado sobre dado, ou seja, são conjuntos de elementos que permitem uma descrição normalizada das fontes em meio eletrônico, com o objetivo de facilitar a sua descoberta, localização e utilização.

Foram criados vários padrões de descrição de recursos de informação como o padrão Dublin Core, proposto pela Dublin Core Metadata Initiative (DCMI). O DC pode ser entendido como um "[...] conjunto de elementos de metadados planejado para facilitar a descrição de recursos eletrônicos." (SOUZA; VENDRUSCULO; MELO, 2000, p. 93). Segundo o DCMI (2019), o padrão DC é composto por 15 elementos para a descrição de conteúdo, denominados Dublin Core Metadata Element Set (DCMES). Tais elementos serão aqui apresentados e descritos tendo como base o DCMI (2019):

a) assunto: tópico do recurso. Normalmente será representado por palavras-chave, frases-chave ou códigos de classificação;

b) cobertura: envolve tópico espacial e aplicabilidade espacial do recurso; 
c) contribuinte: entidade responsável por fazer contribuições para o recurso;

d) criador: entidade principal responsável por fazer o recurso;

e) data: ponto ou período de tempo associado a um evento no ciclo de vida do recurso;

f) descrição: um resumo, um sumário, uma representação gráfica ou um texto livre do recurso;

g) direitos: informações sobre direitos mantidos e sobre o recurso;

h) editor: entidade responsável por disponibilizar o recurso;

i) fonte: recurso relacionado do qual o recurso descrito é derivado;

j) formato: referente ao formato de arquivo, meio físico ou dimensões do recurso;

k) identificador: referência inequívoca ao recurso dentro de um determinado contexto;

l) idioma: linguagem do recurso;

m) relação: relacionamento com outros documentos;

n) tipo: natureza ou gênero do recurso; e

o) título: nome dado ao recurso. Nome pelo qual o recurso é formalmente conhecido.

As vantagens do padrão de metadados DC podem ser detectadas ao se analisar as seguintes características apresentadas por Gracio (2002): simplicidade, uma vez que o referido padrão pode ser gerado pelo responsável do documento sem que o mesmo necessite de treinamentos extensos; interoperabilidade semântica, por possuir um modelo comum de descrição; consenso internacional, pois possui a participação de mais de vinte países no DCMI para a busca de escopo internacional na Web e de uma infraestrutura adequada; extensibilidade, por ser um modelo flexível que permite acréscimo de elementos para atender uma necessidade de descrição de um determinado recurso; e flexibilidade, uma vez que seus elementos são opcionais e modificáveis. 


\section{METODOLOGIA}

Trata-se de estudo com abordagem qualitativa e de caráter descritivo e exploratório. O delineamento da investigação se deu por meio de uma pesquisa bibliográfica e documental. A coleta de dados foi realizada por meio da análise dos campos e subcampos dos registros de marcas. Dessa forma, foi estudada a estrutura de dados apresentados na base de dados de marcas do INPI, comparando-as com as recomendações do esquema de metadados do padrão DC, para fins de descrição de objetos na internet. Assim, a técnica empregada para análise dos dados foi a análise comparativa entre campos de registro e metadados.

É primordial que se defina a população de estudo e a amostra, delimitando, assim, o foco do trabalho. Este estudo, portanto, possui como população a base de dados especializada em marcas do INPI; e como amostra são destacados dois registros de marcas pertencentes à essa base de dados. Dessa forma, a técnica de amostragem utilizada é a amostragem não probabilística, por acessibilidade.

Foi realizado um estudo piloto, a fim de verificar a possibilidade de equivalência entre os campos da base de dados de marcas do INPI com as recomendações do padrão DC.

Dessa forma, foi selecionada da base de dados especializada em marcas do INPI dois registros de marcas para análise de seus campos e subcampos: 0 registro da marca Galera Record e o registro da marca Rocco. Estas foram escolhidas levando em conta o mesmo ramo de atuação no mercado, ou seja, o mercado editorial e livreiro.

\section{RESULTADOS}

Tendo em vista a necessidade de análise da estrutura de dados na base de dados do INPI, no escopo da pesquisa, foram localizados os registros das duas marcas que foram objeto do estudo: Galera Record e Rocco, conforme Figuras 1 e 2, abaixo, discriminadas: 
Figura 1 - Registro da marca "Galera Record" na base de dados do INPI Figura 2

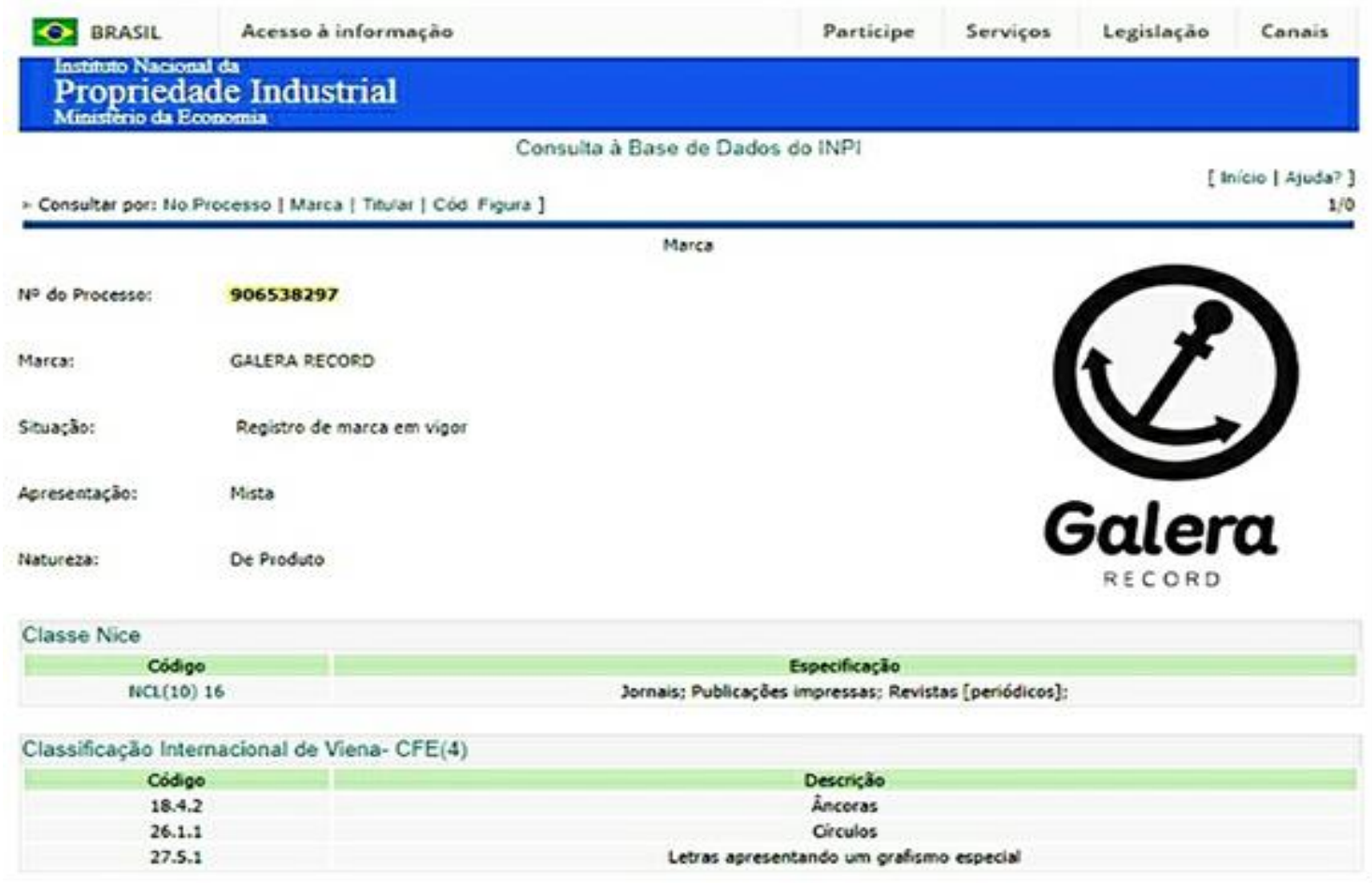

- Registro da marca "Galera Record" na base de dados do INPI

Figura 3 - Registro da marca "Galera Record" na base de dados do INPI

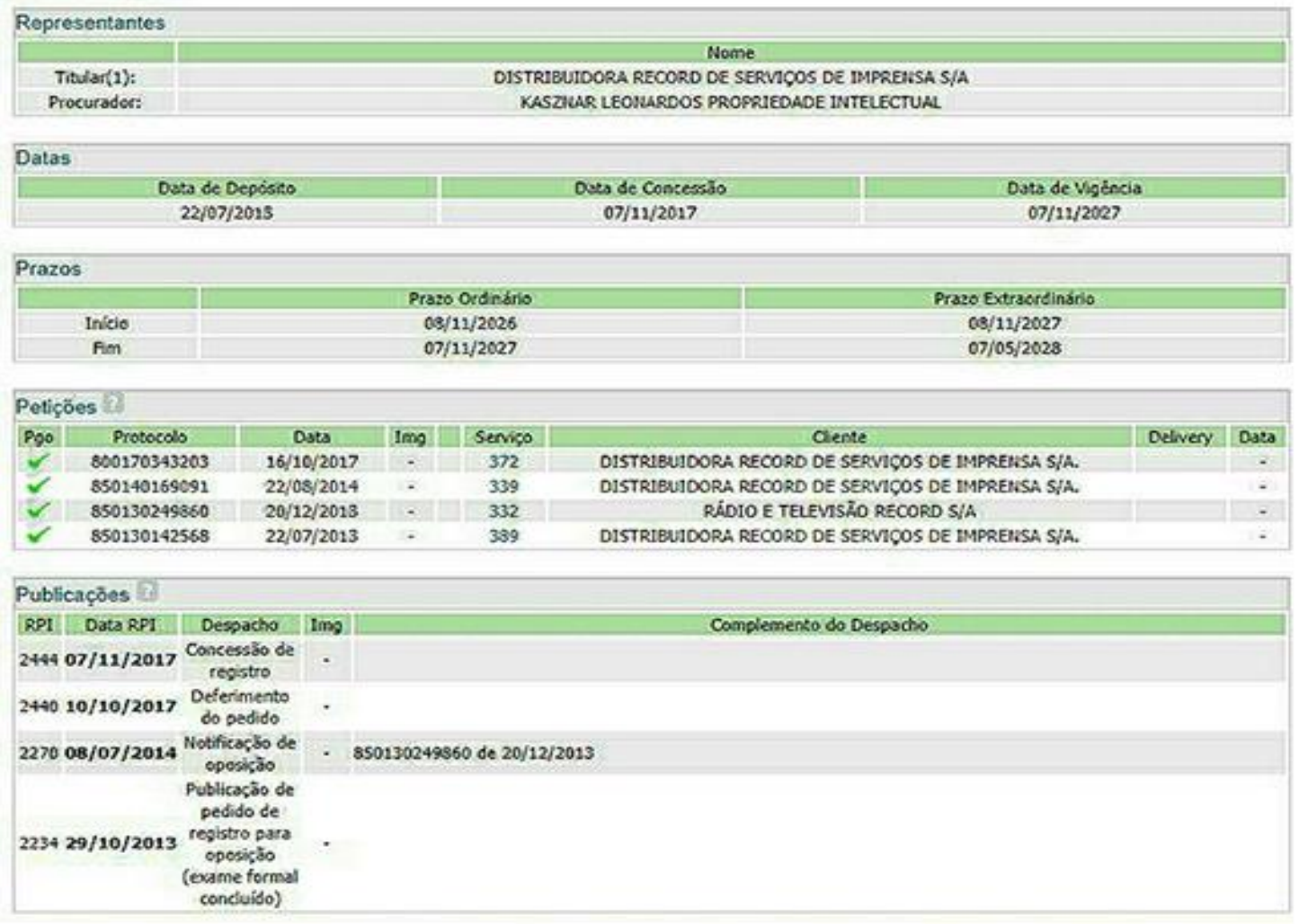

Fonte: INPI (2019).

Inf. Inf., Londrina, v. 26, n. 1, p. 391 - 414, jan./mar. 2021. 
Figura 4 - Registro da marca "Rocco" na base de dados do INPI

\begin{tabular}{|c|c|c|c|c|c|}
\hline O2 BRASIL & Acesso à informaçâ० & Participe & Serviços & Legislação & Canais \\
\hline
\end{tabular}

\section{Consulta à Base de Dados do INPI}

$\begin{array}{ll}\text { Wo do Processe: } & 821283685 \\ \text { Marcs: } & \text { Rocco } \\ \text { Stuaclo: } & \text { Registro de marca em vipor } \\ \text { Apresentasio: } & \text { Masta } \\ \text { Natureza: } & \text { De Prosuto }\end{array}$

\begin{tabular}{|c|c|}
\hline \multicolumn{2}{|l|}{ Classe Nice } \\
\hline Codiso & Especificasio \\
\hline $\operatorname{na}(7) 16$ & UNROS, JORUALS E REVISTAS (COMERCIALIZACZO)); \\
\hline \multicolumn{2}{|c|}{ Classificaçåo Internacional de Viena. CFE(4) } \\
\hline Codigo & Descristo \\
\hline 27.5 .1 & Letras apresentando un grafismo especial \\
\hline
\end{tabular}

\begin{tabular}{|c|c|}
\hline Representantes & Nome \\
\hline Titular(1): & EOTORA ROCCO LTDA \\
\hline Procurador: & O PRÓPRIO. \\
\hline
\end{tabular}

\begin{tabular}{|c|c|c|}
\hline Datas & & \\
\hline & Data de Concessto & Data de Vigéncia \\
\hline $18 / 12 / 1998$ & $30 / 04 / 2002$ & $30 / 04 / 2022$ \\
\hline
\end{tabular}

\begin{tabular}{|c|c|c|}
\hline Prazos & & \\
\hline & Prazo Ordinśrio & Prazo Extrsordinário \\
\hline Inicio & $01 / 05 / 2021$ & $01 / 05 / 2022$ \\
\hline Fim & $30 / 04 / 2022$ & $30 / 10 / 2022$ \\
\hline
\end{tabular}

\begin{tabular}{|c|c|c|c|c|c|c|c|}
\hline \multicolumn{8}{|c|}{ Petiçòes } \\
\hline Pge & Protocolo & Dats & Img & Serviso & Clente & Delivery & Data \\
\hline$\checkmark$ & 800110117535 & $25 / 07 / 2011$ & 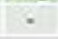 & 374 & EOITORA ROCCO LTDA & & . \\
\hline
\end{tabular}

\begin{tabular}{|c|c|c|c|c|}
\hline \multicolumn{5}{|c|}{ Publicaçōes } \\
\hline$R P 1$ & Data RPI & Despacho & Img & Complemento do Despacho \\
\hline 2267 & $17 / 06 / 2014$ & $\begin{array}{l}\text { Deferimento } \\
\text { da petiç̧o }\end{array}$ & - & $\begin{array}{l}\text { Protocolo: } 800110117535 \text { (2S/07/2011) } \\
\text { Petiçăo (tipo): Procrogaçäo de registro de marca e expediçăo de certificado no prazo ordinário (374.1) } \\
\text { Titular: EDITORA ROCCO LTDA } \\
\text { Detalhes do despacho:CONFORME ART. } 133 \text { DA LPL. }\end{array}$ \\
\hline 1634 & $30 / 04 / 2002$ & 400 & - & \\
\hline 1605 & $09 / 10 / 2001$ & 351 & $\cdot$ & \\
\hline 1468 & $23 / 02 / 1999$ & 003 & - & \\
\hline
\end{tabular}

Fonte: INPI (2019).

Analisando as Figuras 1 e 2 acima, pode-se perceber que os registros das

Inf. Inf., Londrina, v. 26, n. 1, p. $391-414$, jan./mar. 2021. 
marcas das editoras apresentadas possuem um total de oito campos principais: Marca; Classe Nice1; Classificação Internacional de Viena2; Representantes; Datas; Prazos; Petições; Publicações. Entretanto, os referidos campos englobam outros campos relacionados a eles, chamados aqui de subcampos.

Assim, observa-se que os subcampos Número do Processo; Marca; Situação; Apresentação e Natureza, encontram-se relacionados ao campo principal "Marca". Dessa forma, também é possível afirmar que os subcampos Código e Especificação estão englobados no campo "Classe Nice". Já o campo principal "Classificação Internacional de Viena" conta com os subcampos Código e Descrição. No campo "Representantes", os subcampos que aparecem no registro são Titular (1) e Procurador. O campo "Datas" possui Data de Depósito, Data de Concessão e Data de Vigência como subcampos. No que diz respeito ao campo "Prazo", o início e o fim do Prazo Ordinário e do Prazo Extraordinário são seus subcampos. O campo principal "Petições" possui os seguintes campos relacionados: Pago (Pgo); Protocolo; Data; Imagem (Img); Serviço; Cliente; Delivery e Data. Por fim, os subcampos Revista de Propriedade Industrial (RPI); Data RPI; Despacho; Img e Complemento do Despacho estão relacionados com o campo principal "Publicações".

Com campos e subcampos apresentados segundo suas relações, é necessário compreender quais deles são adequados para efetuar a análise de equivalência com os elementos do padrão DC.

Nesse aspecto, os subcampos da base de marcas foram agrupados e organizados, de forma que pudessem ser descritos, visando otimizar a análise de sua estrutura, conforme Quadro 1, abaixo:

Quadro 1 - Análise dos campos e subcampos do registro de marcas

\begin{tabular}{|c|c|}
\hline \multicolumn{2}{|c|}{ Campo principal: Marcas } \\
\hline Subcampos & \multicolumn{1}{c|}{ Observações } \\
\hline Número do Processo & $\begin{array}{c}\text { número gerado pelo sistema no momento da montagem do } \\
\text { processo. É composto por 9 dígitos e faz uma referência }\end{array}$ \\
\hline
\end{tabular}

${ }^{1}$ Classificação internacional de produtos e serviços composta por 45 classes (INPI, 2019).

2 "[...] classificação de ordem prática, usada para facilitar as buscas de anterioridade de elementos figurativos no momento do exame de marcas." (INPI, 2019). 


\begin{tabular}{|c|c|}
\hline & livre de ambiguidade ao recurso. \\
\hline Marca & Local de registro do nome dado ao recurso. \\
\hline Situação & $\begin{array}{c}\text { Descreve o estado do registro do recurso, permitindo saber } \\
\text { se o mesmo está ou não em vigor. }\end{array}$ \\
\hline Apresentação & $\begin{array}{l}\text { Refere-se às formas gráficas de apresentação do recurso, } \\
\text { agregando valor à descrição do mesmo. }\end{array}$ \\
\hline Natureza & $\begin{array}{c}\text { Especifica a natureza ou o gênero do recurso, agregando } \\
\text { valor à descrição do mesmo. }\end{array}$ \\
\hline \multicolumn{2}{|r|}{ Campo principal: Classe Nice } \\
\hline Subcampos & Observações \\
\hline Código & $\begin{array}{l}\text { Apresenta o código do sistema de classificação de produtos } \\
\text { e serviços para pedidos de registro de marcas. Consiste em } \\
45 \text { classes. }\end{array}$ \\
\hline Especificação & $\begin{array}{c}\text { Fornece a descrição de informações gerais sobre o tipo de } \\
\text { produtos ou serviços abrangidos. Tem finalidade de } \\
\text { sinalizar o tópico do recurso. }\end{array}$ \\
\hline \multicolumn{2}{|c|}{ Campo principal: Classificação Internacional de Viena - CFE (4) } \\
\hline Subcampos & Observações \\
\hline Código & $\begin{array}{l}\text { Código da Classificação Internacional de Elementos } \\
\text { Figurativos de Marcas. Facilita a busca de anterioridades. } \\
\text { Possui } 29 \text { categorias que contemplam subcategorias. }\end{array}$ \\
\hline Descrição & $\begin{array}{c}\text { Descreve os elementos figurativos do recurso, agregando } \\
\text { valor à descrição }\end{array}$ \\
\hline \multicolumn{2}{|r|}{ Campo principal: Representantes } \\
\hline Subcampos & Observações \\
\hline Titular (1) & $\begin{array}{c}\text { Sinaliza a entidade responsável pela criação do conteúdo } \\
\text { do recurso. }\end{array}$ \\
\hline Procurador & $\begin{array}{c}\text { Agente legal e credenciado que pode representar o } \\
\text { requerente perante ao INPI. }\end{array}$ \\
\hline \multicolumn{2}{|r|}{ Campo principal: Datas } \\
\hline Subcampos & Observações \\
\hline Data de Depósito & $\begin{array}{l}\text { Data em que o depósito do recurso foi efetuado. Nesse } \\
\text { momento, o requerente ainda não pode usufruir dos direitos } \\
\text { que envolvem o registro de uma marca, ele apenas possui } \\
\text { uma "expectativa de direito". Apesar disso, esse subcampo } \\
\text { está associado a um evento no ciclo de vida do recurso. }\end{array}$ \\
\hline Data de Concessão & $\begin{array}{l}\text { Data em que o requerente obtém, integralmente, o registro } \\
\text { do recurso junto com os direitos a ele relacionados. } \\
\text { Também está associado ao ciclo de vida do recurso. }\end{array}$ \\
\hline Data de vigência & $\begin{array}{l}\text { Data limite da validade do registro do recurso, bem como } \\
\text { os direitos garantidos ao requerente. Possui validade de } 10 \\
\text { anos, podendo ser renovada constantemente. Está } \\
\text { associado ao ciclo de vida do recurso. }\end{array}$ \\
\hline
\end{tabular}




\begin{tabular}{|c|c|}
\hline \multicolumn{2}{|r|}{ Campo principal: Prazos } \\
\hline Subcampos & Observações \\
\hline Prazo Ordinário & $\begin{array}{l}\text { Apresenta o período de tempo, início e fim, que o } \\
\text { requerente tem para pagar uma taxa de concessão. A } \\
\text { marca só é realmente deferida se o requerente faz o } \\
\text { pagamento dessa taxa dentro do tempo estipulado. Esse } \\
\text { subcampo é voltado para fins de controle administrativo do } \\
\text { INPI. }\end{array}$ \\
\hline Prazo Extraordinário & $\begin{array}{l}\text { Apresenta o período de tempo extra, início e fim, } \\
\text { disponibilizado para o pagamento da taxa de concessão, } \\
\text { porém agora com um acréscimo no valor. O não } \\
\text { pagamento dessa taxa gera o arquivamento do recurso. } \\
\text { Também é um dado com fins de controle administrativo. }\end{array}$ \\
\hline \multicolumn{2}{|r|}{ Campo principal: Petições } \\
\hline Subcampos & Observações \\
\hline Pgo & $\begin{array}{c}\text { Confirma se pagamentos de diversas naturezas do GRU } \\
\text { foram efetuados ou não. Possui apenas valor } \\
\text { administrativo. }\end{array}$ \\
\hline Protocolo & $\begin{array}{c}\text { Número de identificação do GRU. Possui } 12 \text { dígitos. É } \\
\text { informação de caráter administrativo do INPI. }\end{array}$ \\
\hline Data & $\begin{array}{c}\text { Apresenta a data em que o pagamento do GRU foi } \\
\text { efetuado. Também possui caráter de controle administrativo } \\
\text { do Instituto. }\end{array}$ \\
\hline Img & Não foram encontradas informações sobre esse subcampo. \\
\hline Serviço & $\begin{array}{c}\text { Está relacionado ao tipo de serviço pelo qual o pagamento } \\
\text { da GRU foi efetuado. O tipo de serviço é representado por } \\
\text { um código numérico correspondente e já estabelecido } \\
\text { anteriormente. É uma informação para controle } \\
\text { administrativo. }\end{array}$ \\
\hline Cliente & $\begin{array}{l}\text { Pessoa física ou jurídica que solicitou o serviço que gerou a } \\
\text { GRU. Esse subcampo tem o controle administrativo como } \\
\text { finalidade, portanto não é relevante para a recuperação da } \\
\text { informação. }\end{array}$ \\
\hline Delivery & Não foram encontradas informações sobre esse subcampo. \\
\hline Data & Não foram encontradas informações sobre esse subcampo. \\
\hline \multicolumn{2}{|r|}{ Campo principal: Publicações } \\
\hline Subcampos & Observações \\
\hline RPI & $\begin{array}{l}\text { Apresenta o número da Revista de Propriedade Industrial } \\
\text { na qual foi publicada determinada informação sobre o } \\
\text { recurso. É valioso para a recuperação da informação e } \\
\text { mantêm relação com o recurso em si. }\end{array}$ \\
\hline Data da RPI & $\begin{array}{l}\text { Data da publicação da Revista de Propriedade Industrial } \\
\text { que contém determinada informação sobre o recurso. É } \\
\text { possível recuperar a RPI desejada pela data. }\end{array}$ \\
\hline
\end{tabular}




\begin{tabular}{|c|c|}
\hline Despacho & $\begin{array}{c}\text { Apresenta a petição sobre um recurso. A referida petição é } \\
\text { publicada na RPI a fim de possibilitar o acompanhamento } \\
\text { de um pedido. }\end{array}$ \\
\hline Img & Não foram encontradas informações sobre esse subcampo. \\
\hline $\begin{array}{c}\text { Complemento de } \\
\text { Despacho }\end{array}$ & $\begin{array}{c}\text { Pode apresentar o protocolo de determinada petição, a } \\
\text { data da petição, o tipo da petição, o titular da petição e } \\
\text { outros detalhes do despacho. }\end{array}$ \\
\hline
\end{tabular}

Fonte: Os autores (2019).

A disponibilização apresentada no Quadro 1, permite verificar quais campos e subcampos que constituem o registro das marcas na base de dados do INPI são passíveis de serem relacionados com os elementos do padrão DC. Além disso, identificou-se quais campos e subcampos são indispensáveis para a busca e recuperação da informação na base de dados especializada em marcas comerciais do Instituto em questão; são eles: Número do Processo; Marca; Situação; Apresentação; Natureza; Código (Nice); Especificação; Código (CFE); Descrição; Titular (1); Procurador; Data de Depósito; Data de Concessão; Data de Vigência; RPI; e Data RPI.

Baseado nas informações obtidas (Quadro 1), foi possível identificar se havia equivalência entre os elementos do DC e os campos do Sistema de Marcas (SM), conforme apresentado no Quadro 2.

Quadro 2 - Equivalência entre os elementos do padrão DC e dos campos do SM

\begin{tabular}{|c|c|c|}
\hline $\begin{array}{c}\text { Elementos do } \\
\text { Padrão Dublin } \\
\text { Core }\end{array}$ & $\begin{array}{c}\text { Campos } \\
\text { correspondentes } \\
\text { do Sistema de } \\
\text { Marcas }\end{array}$ & Justificativa \\
\hline Título & Marca & $\begin{array}{c}\text { Ambos os elementos fornecem o nome dado } \\
\text { ao recurso, podendo ser relacionados como } \\
\text { equivalentes. }\end{array}$ \\
\hline Criador & Titular & $\begin{array}{c}\text { Em ambos os casos representam a entidade } \\
\text { responsável pela criação do conteúdo do } \\
\text { recurso, havendo, assim, relação direta entre } \\
\text { os campos. }\end{array}$ \\
\hline Descrição & $\begin{array}{c}\text { Código (CFE) }+ \\
\text { Descrição (CFE) }\end{array}$ & $\begin{array}{c}\text { São entendidos como equivalentes pois } \\
\text { relatam o conteúdo do recurso. No caso do } \\
\text { padrão Dublin Core a descrição é feita a } \\
\text { partir de resumos, textos livres ou sumários. } \\
\text { Já no Sistema de Marcas, há a descrição } \\
\text { dos elementos que compõem a marca. }\end{array}$ \\
\hline Assunto & $\begin{array}{c}\text { Código (Nice) }+ \\
\text { Especificação }\end{array}$ & $\begin{array}{c}\text { Apresentam o tema do conteúdo do recurso, } \\
\text { ou seja, a categoria em que o mesmo se }\end{array}$ \\
\hline
\end{tabular}




\begin{tabular}{|c|c|c|}
\hline & (Nice) & $\begin{array}{l}\text { encaixa. Então, é possível estabelecer uma } \\
\text { relação de equivalência entre esses campos. }\end{array}$ \\
\hline Cobertura & - & $\begin{array}{l}\text { Não possui campo correspondente no } \\
\text { Sistema de Marcas. }\end{array}$ \\
\hline Publicador & - & $\begin{array}{l}\text { O publicador, no caso das marcas, seria o } \\
\text { próprio INPI, que atesta ou não o registro de } \\
\text { uma marca. Entretanto, não há um campo } \\
\text { equivalente no Sistema de Marcas. }\end{array}$ \\
\hline Contribuinte & Procurador & $\begin{array}{l}\text { Apesar de o procurador não influenciar no } \\
\text { processo de criação de uma marca, ele } \\
\text { contribui para o registro da mesma. Dessa } \\
\text { forma, sugere-se que os campos sejam } \\
\text { identificados como equivalentes. }\end{array}$ \\
\hline Tipo & $\begin{array}{l}\text { Apresentação + } \\
\text { Natureza }\end{array}$ & $\begin{array}{l}\text { Os campos representam a natureza ou o } \\
\text { gênero do recurso, portanto, possuem } \\
\text { relação de equivalência. }\end{array}$ \\
\hline Identificador & $\begin{array}{l}\text { Número do } \\
\text { Processo }\end{array}$ & $\begin{array}{c}\text { Ambos os campos fazem uma referência } \\
\text { livre de ambiguidade ao recurso. }\end{array}$ \\
\hline Data & $\begin{array}{l}\text { Data de Depósito } \\
\text { + Data de } \\
\text { Concessão + } \\
\text { Data de Vigência }\end{array}$ & $\begin{array}{c}\text { Tais campos estão associados ao ciclo de } \\
\text { vida do recurso, assim, estão relacionados e } \\
\text { são equivalentes. }\end{array}$ \\
\hline Formato & - & $\begin{array}{c}\text { Não possui campo correspondente no } \\
\text { Sistema de Marcas. }\end{array}$ \\
\hline Idioma & - & $\begin{array}{l}\text { O registro da marca deve ser feito na língua } \\
\text { portuguesa, uma vez que se trata do Instituto } \\
\text { Nacional do Brasil, dessa forma, o idioma } \\
\text { dos registros é o português, mas não há um } \\
\text { campo equivalente no Sistema de Marcas. } \\
\text { Para que houvesse tal relação, teria que } \\
\text { haver algum campo que apresentasse o país } \\
\text { de origem da marca, por exemplo. }\end{array}$ \\
\hline Fonte & - & $\begin{array}{l}\text { Não há campo ambivalente no Sistema de } \\
\text { Marcas. }\end{array}$ \\
\hline Relação & RPI + Data RPI & $\begin{array}{c}\text { Refere-se a algo relacionado ao recurso. A } \\
\text { RPI é um documento que mantêm relação } \\
\text { com o recurso em si, uma vez que apresenta } \\
\text { informações sobre ele. Nesse caso, tais } \\
\text { campos podem ser considerados } \\
\text { equivalentes. }\end{array}$ \\
\hline Direitos & Situação & $\begin{array}{c}\text { Apresentam informação sobre os direitos } \\
\text { assegurados, portanto podem ser entendidos } \\
\text { como campos equivalentes. }\end{array}$ \\
\hline
\end{tabular}

Fonte: Os autores (2019).

\section{CONCLUSÕES}

O padrão DC permite a localização, uso, intercâmbio e o reuso de 
informações a partir da descrição normalizada das fontes de informação em meio eletrônico. Além disso, o mesmo é reconhecido pela sua interoperabilidade, flexibilidade, simplicidade e extensibilidade, características necessárias para a elaboração de modelos que atendam às necessidades de descrição de um determinado recurso. Por essa razão, é possível que se modifique ou acrescente elementos para atender outros tipos de documentos, como as marcas, por exemplo. Essas características facilitam o tratamento das informações, facilitando, igualmente sua busca e recuperação.

A utilização de metadados visa "[...] tornar a descrição dos recursos eletrônicos adequada para que a pesquisa e a recuperação das informações armazenadas nestes recursos possam ser rápidas e, principalmente, eficientes." (GRACIO, 2002, p.102). Ainda segundo o autor, muitos motivos são apontados para a utilização de metadados, como, por exemplo, o controle do grande volume de dados; disponibilização; catalogação; organização; uso de padrões abertos; indexação; intercâmbio; gerenciamento e descrição de informações. No entanto, o principal objetivo é tornar a informação disponível e de fácil acesso para o usuário final, possibilitando que encontre os dados desejados.

A pesquisa mostrou que os campos da base de dados de marcas do INPI, embora apresentem descrição de dados estruturados, ainda não estão adequados aos padrões recomendados para a descrição de objetos digitais relativos ao esquema de metadados Dublin Core. Nesse aspecto, o estudo piloto, apresentou as respectivas possíveis equivalências entre os campos, no sentido de tornar possível a padronização para os registros de marcas, com enfoque na Web.

É primordial, antes de tudo, compreender que qualquer sistema de informação necessita buscar atender aos seus usuários atuais e potenciais. Desta forma, é imperativo tratar os tipos de informações de que necessitam, a fim de desenvolver um sistema que atenda suas necessidades informacionais e que propicie a busca e a recuperação da informação de forma eficiente e eficaz. Cunha (1982) afirma que o estudo de usuários força uma revisão de papéis desempenhados pelos centros de documentação e informação ao fazer com que tais instituições retornem ao objetivo primordial de prestação de serviços aos 
usuários, satisfazendo suas necessidades de informação. "É geralmente reconhecido que o sucesso de um organismo de informação científicotecnológica [...] depende do conhecimento que se tem das necessidades de informação das pessoas que utilizam seus serviços." (CUNHA, 1982, p. 6).

Recomenda-se, também, o aprofundamento de estudos para adequação dos campos da base de marcas do INPI aos metadados do esquema Dublin Core, uma vez que a adoção de tal esquema, ao possuir um conjunto básico, extensível e flexível de elementos de descrição, facilita o acesso e a recuperação da informação. Observa-se que o modelo atual de registro de marcas comporta informações voltadas para o controle administrativo, necessitando ser melhor desenvolvida para atendimento, não somente ao requerente, mas também para fins de pesquisa acadêmica na área de marcas.

Ainda, é importante, também, a capacitação de profissionais bibliotecários para que possam contribuir no desenvolvimento de projetos de descrição para objetos na internet, em base de dados de marcas. Nesse aspecto, cabe salientar a relevância de capacitação dos profissionais, tanto no âmbito das novas tecnologias de comunicação e informação (TIC), quanto em termos de propriedade industrial.

\section{CONSIDERAÇÕES FINAIS E ESTUDOS FUTUROS}

Há muitos anos as marcas foram introduzidas na sociedade como forma de os comerciantes identificarem os seus produtos e/ou serviços, além de se diferenciarem da concorrência e de apelarem ao consumo. Com a expansão mercadológica surgiram novas empresas e marcas disponíveis no mercado e, em decorrência disso, houve a necessidade de proteção.

Atualmente, as marcas são objetos passíveis de proteção por se enquadrarem no universo da Propriedade Industrial. Como foi abordado, o INPI é o responsável pelo registro e concessão de marcas em todo o território nacional, sendo assim, dispõe de uma base de dados específica de marcas, que apresenta características singulares e específicas para atendimento aos requerentes dos pedidos formulados junto ao Instituto. 
Os resultados preliminares, demonstram uma inadequação parcial dos campos da base de dado eletrônica de marcas do INPI com a descrição de objetos digitais da estrutura de metadados DC. Entende-se que a adequação dos campos possibilitaria a criação de condições para ampliar e refinar a busca e a recuperação das informações pelos usuários, além de contribuir para a integração e compartilhamento de dados e interoperabilidade entre sistemas.

Decerto, o estudo busca contribuir para expandir o conhecimento para o campo de atuação dos profissionais bibliotecários, uma vez que analisa a estrutura de dados apresentados na base do INPI, comparando-a com as recomendações do esquema de metadados Dublin Core. Desta forma, trata-se de uma nova abordagem que poderá ser desenvolvida em estudos futuros na área de Biblioteconomia, mais especificamente em representação da informação.

O trabalho também aponta para a necessidade de aprofundamento de estudos que investiguem sistemas de informação em matéria de propriedade industrial, a fim de explorar diferentes estruturas de documentação dos mais variados objetos eletrônicos, de modo a buscar soluções viáveis para o aprimoramento do sistema, tendo como base as recomendações do padrão DC.

\section{REFERÊNCIAS}

ALBRECHT, Rogéria F.; OHIRA, Maria Lourdes B. Base de dados: metodologia para seleção e coleta de documentos. ACB: Biblioteconomia em Santa Catarina, Florianópolis, v. 5, n. 5, p. 131-144, 2000. Disponível em: https://revista.acbsc.org.br/racb/article/view/347/411. Acesso em: 18 mar. 2019.

BARBOSA, Denis B. Uma introdução à propriedade intelectual. 2. ed. Rio de Janeiro: Lumen Juris, 2003. Disponível em:

http://www.denisbarbosa.addr.com/arquivos/livros/umaintro2.pdf. Acesso em: 09 mar. 2019.

BRASIL. Lei oㅜ 9.279, de 14 de maio de 1996. Regula direitos e obrigações relativos à propriedade industrial, Brasília, DF, 15 maio. 1996. Disponível em: https://www.planalto.gov.br/ccivil_03/leis/19279.htm. Acesso em: 01 nov. 2019.

CAMPELLO, Bernadete S.; CENDÓN, Beatriz V.; KREMER, Jeanette M.

Fontes de informação para pesquisadores e profissionais. Belo Horizonte: 
UFMG, 2000. Disponível em: https://books.google.com.br/books?hl=pt-

$B R \& I r=\& i d=G b P c-$

E5WQHAC\&oi=fnd\&pg=PA21\&dq=usu\%C3\%A1rios+de+fontes+de+informa\%C $3 \% A 7 \% C 3 \% A 30 \&$ ots=oyttcRiCkX\&sig=WSyFMylZMml32ac8c1S4LGxyIWE\#v= onepage\&q=usu\%C3\%A1 rios\%20de\%20fontes\%20de\%20informa\%C3\%A7\%C 3\%A3o\&f=false. Acesso em: 06 mar. 2019.

CUNHA, Murilo B. da. Metodologias para estudo dos usuários de informação científica e tecnológica. Revista de Biblioteconomia de Brasília, Brasília, DF, v. 10, n. 2, p. 5-19, 1982. Disponível em:

https://s3.amazonaws.com/academia.edu.documents/30984118/CUNHA_1982. pdf?response-content-

disposition=inline\%3B\%20filename\%3DMetodologias_para_estudo_dos_usuari os_de.pdf\&X-Amz-Algorithm=AWS4-HMAC-SHA256\&X-Amz-

Credential=AKIAIWOWYYGZ2Y53UL3A\%2F20191110\%2Fus-east-

1\%2Fs3\%2Faws4_request\&X-Amz-Date=20191110T153115Z\&X-Amz-

Expires $=3600 \& X-A m z-S i g n e d H e a d e r s=h o s t \& X-A m z-$

Signature $=b 04 d 2 b a b a 42 e e f c 9697$ eae1a7a31392322c61b2ada697eae8bc1b5e 75c45322a. Acesso em: 10 nov. 2019.

CUNHA, Murilo B. da. Para saber mais: fontes de informação em ciência e tecnologia. Brasília, DF: Briquet de Lemos, 2001. Disponível em: http://repositorio.unb.br/bitstream/10482/15121/3/LIVRO_ParaSaberMais.pdf. Acesso em: 07 mar. 2019.

DCMI. Dublin core metadata elemento set. Disponível em: http://www.dublincore.org/specifications/dublin-core/dces/. Acesso em: 22 maio 2019.

GILLILAND, A. J. Setting the Stage. In: BACA, Murtha (Ed.). Introduction to Metadata. 3. ed. Los Angeles: Getty Research Institute, 2016. Cap. 5. p. 8-25. Disponível em: http://www.getty.edu/publications/intrometadata/setting-thestage/. Acesso em: 22 maio 2019.

GRACIO, José Carlos A. Metadados para a descrição de recursos da Internet: o padrão Dublin Core, aplicações e a questão da interoperabilidade. 2002. 127 f. Dissertação (Mestrado em Ciência da Informação) - Faculdade de Filosofia e Ciências, Universidade Estadual Paulista, Marília, 2002. Disponível em: https://www.marilia.unesp.br/Home/Pos-

Graduacao/Cienciadalnformacao/Dissertacoes/gracio_jca_dr_mar.pdf. Acesso em: 22 maio 2019.

INPI. Classificação de produtos e serviços. Disponível em: http://www.inpi.gov.br/menu-servicos/marcas/classificacao. Acesso em: 07 jan. 2020.

INPI. Introdução à Propriedade Intelectual. In: Curso geral da Propriedade Intelectual. Rio de Janeiro: INPI, 2016. cap. 2, p 1-14. 
INPI. Marcas. In: Curso geral de Propriedade Intelectual. Rio de Janeiro: INPI, 2016. cap. 4, p. 1-22.

INPI. Galera Record. Disponível em: https://gru.inpi.gov.br/pePl/servlet/MarcasServletController?Action=detail\&CodP edido=2893600. Acesso em: 16 nov. 2019.

INPI. Instituto Nacional da Propriedade Industrial. Disponível em: http://www.inpi.gov.br/sobre/estrutura. Acesso em: 10 nov. 2019.

INPI. Manual de marcas. Disponível em: http://manualdemarcas.inpi.gov.br/projects/manual/wiki/02_O_que_\%C3\%A9_ marca\#24-Princ\%C3\%ADpios-legais. Acesso em: 02 mar. 2019.

INPI. Rocco. Disponível em: https://gru.inpi.gov.br/pePl/servlet/MarcasServletController?Action=detail\&CodP edido=1117918. Acesso em: 16 nov.2019.

LIESEN, Maurício. Communicatio: communio: koinonia. Questões

Transversais: revista de epistemologias da comunicação, São Leopoldo, v. 2, n. 4, p. 89-97, jul./dez. 2014. Disponível em:

http://revistas.unisinos.br/index.php/questoes/article/view/9624. Acesso em: 19 jun. 2019.

MORIGI, Valdir J; BONOTTO, Marta E. K. Kling. A narrativa musical, memória e fonte de informação afetiva. Em Questão, Porto Alegre, v. 10, n.1, p.143-161, jan./jun. 2004. Disponível em:

https://seer.ufrgs.br/EmQuestao/article/view/88/47. Acesso em: 06 mar. 2019.

\section{NAÇÕES UNIDAS BRASIL. Organização Mundial da Propriedade}

Intelectual. Disponível em: https://nacoesunidas.org/agencia/ompi/. Acesso em: 09 mar. 2019.

PINHO, J. B. O poder das marcas. 3.ed. São Paulo: Summus Editorial, 1996. Disponível em: https://books.google.com.br/books?hl=pt-

$B R \& \mid r=\& i d=x g 5 x X+X B r B s C \& o i=f n d \& p g=P A 11 \& d q=0+r e g i s t r o+d a s+$ marcas \&ots =kplw4a5Z5S\&sig=Tc8yxEV_luFAzFOVIP4M_Y5w_sM\#v=onepage \&q=0\%20re gistro\%20das\%20marcas\&f=false. Acesso em: 07 mar. 2019.

REITZ, Joan M. ODLIS: Online Dictionary of Library and Information Science. Danbury: CSU, 2001. Disponível em: http://vlado.fmf.unilj.si/pub/networks/data/dic/odlis/odlis.pdf. Acesso em: 06 mar. 2019.

SOUZA, Marcia Izabel F.; VENDRUSCULO, Laurimar G.; MELO, Geane Cristina. Metadados para a descrição de recursos de informação eletrônica: utilização do padrão Dublin Core. Ciência da Informação, Brasília, DF, v. 29, n. 1, p. 93-102, 2000. Disponível em: http://www.scielo.br/scielo.php?pid=S010019652000000100010\&script=sci_abstract\&tIng=pt. Acesso em: 20 jun. 2019. 
TORQUATO, Gaudêncio. Cultura, poder, comunicação e imagem: fundamentos da nova empresa. 1. ed. São Paulo: Pioneira, 1991.

VALLEGROS, Paula L. Valor da marca: como agregar valor à marca na indústria farmacêutica, Rio de Janeiro/RJ. 2011. 39 f. dissertação (Pósgraduação em Especialização de Gestão Estratégica de Vendas e Negociação) - Faculdade de Gestão Estratégica de Vendas, Universidade Cândido Mendes, Rio de Janeiro, 2011. Disponível em: http://www.avm.edu.br/docpdf/monografias_publicadas/B002138.pdf. Acesso em: 04 abr. 2019.

VÁSQUEZ, Ruth P. Identidade de marca, gestão e comunicação. Organicom, São Paulo, ano 4, n. 7, p. 201-211, segundo semestre de 2007. Disponível em: http://www.revistas.usp.br/organicom/article/view/138952. Acesso em: 03 mar. 2019.

\title{
SOURCES OF INFORMATION SPECIALIZED IN BRANDS: A LIBRARY SCIENCE OUTLOOK
}

\begin{abstract}
Introduction: The provision and the organization of information in the brands databases of the Nacional Institute of Industrial Property (INPI) are unique, when compared to traditionally known soucers of information, in the Dublin Core metadata scheme. Objective: Observe whether the fields of electronic INPI brands database are suitable for describing brands. Methodology: With the qualitative approach, the technique employed in this research was a comparative analysis of the Dublin Core elements with the fields and subfields in the INPI brands database. Results: The descriptions of brands specialized data are not adequate in the recommended standards for the description of digital objects. Conclusions: It is possible realize the adequacy having the Dublin Core scheme as a paramer, as long as the informational needs of the users are taken into consideration, as well as a proper training among librarians regarding Industrial Property, allowed to creat conditions to facilitate the search and the retrieval of information.
\end{abstract}

Descriptors: Brands. Industrial property. Information sources. Dublin Core. Metadata.

\section{FUENTES DE INFORMACIÓN ESPECIALIZADAS EN MARCAS: UNA MIRADA BIBLIOTECONÓMICA}

\begin{abstract}
RESUMEN
Introducción: Disponibilidad y organización de la información de las bases de datos de marcas del Instituto Nacional de propriedade industrial (INPI) son singular, em comparación com las fuentes de información tradicionalmente conocidas, em el esquema de metadatos Dublin Core. Objetivo: Observar si los campos de las bases de datos de marcas electrónicas del INPI son adecuados para la descripción de la marca. Metodología: Con un enfoque cualitativo, la técnica utilizada fue el análisis comparativo de los elementos estándar de Dublin Core y los campos y subcampos del Sistema de
\end{abstract}


Marcas INPI. Resultados: Las descripciones de datos de marcas especializadas no cumplen con los estándares recomendados para describir objetos digitales. Conclusiones: La adaptación del Sistema de etiquetas al esquema de metadatos Dublin Core es factible, siempre que tenga en cuenta las necesidades de los usuarios y la formación de bibliotecarios en Propiedad Industrial, lo que permite crear condiciones para facilitar la búsqueda y recuperación de información.

Descriptores: Marcas. Propiedad industrial. Fuentes de información. Dublin Core. Metadatos.

Recebido em: 11.02 .2020

Aceito em: 08.02.2021 